\title{
Energy Consumption and Conservation Family Lifestyle: Survey
}

\author{
Meri Algarni \\ School of Science \\ Al-Baha University, Al-Baha, \\ Saudi Arabia
}

\begin{abstract}
Vitality utilization is inspected in the particular setting of home warming consumptions. Examination of home warmth costs crosswise over phases of the family life cycle uncovers an unmistakably unique example than already found when adding up to family vitality expenses were inspected. As opposed to the curvilinear example where uses top amid center phases of the life cycle, this information demonstrates a positive direct relationship where higher expenses are related with elderly buyers. The exploration center is extended to incorporate warmth related protection conduct and additionally uses with an end goal to better comprehend suggestions for arrangement creators and-advertisers.
\end{abstract}

\section{General Terms}

Energy Consumption.

\section{Keywords}

Energy Consumption and Family Life Style.

\section{INTRODUCTION}

As per reports from the Department of Energy, vitality utilization in the normal home could be cut by $60 \%$ using protection techniques and interest in new items to enhance the effectiveness of utilization. Toward this end, DOE (1980) overview comes about demonstrate some preservation related hardware or protecting material was added to half of the lodging units qualified for Federal vitality assess credits in 1977-78. Property holders in 1980 asserted assessment credits on an expected $\$ 4$ billion worth of interests in vitality sparing items fundamentally identified with home warming. Examiners propose that this speculation rate could come to the $\$ 30$ billion level for each year by 1990 (Business Week 1981). As the aftereffect of buyer endeavors from 1973-1980, DOE assesses that vitality utilization per family has been lessened a normal of 12: (Forbes 1982). While numerous strategy leaders would concur that interest for vitality ought to be diminished, not all family units are similarly equipped for changing their utilization examples or putting resources into vitality sparing items. Figuring out where the greatest picks up in enhanced effectiveness of vitality use are probably going to happen is a vital initial phase in the improvement of open preservation programs and also the showcasing of protection related items and administrations. The investigation of protection conduct on customers should be analyzed inside the structure of utilization examples on the off chance that one is to build up a comprehension of the effect of behavioral change. Hitherto the investigation of shopper conduct identified with vitality utilization and preservation has been exceptionally divided. The concentration has had a tendency to be on either utilization examples or protection practices with little exertion coordinated at comprehension the relationship between these two fields of study. The motivation behind this paper is to look at both vitality utilization and preservation designs in the particular setting of home warmth use.

\section{HISTORY OF THE RESEARCH}

The suitable unit of examination for the investigation of both home warming utilization and resulting heat-related preservation conduct is the family unit. While families can be sorted by any number of measurements including pay, the number of individuals, and relative period of individuals, a structure for study which shows a composite of a few measures identified with utilization conduct is family life cycle. In a far-reaching study, Wells and Gubar (1966) archived particular contrasts in utilization designs related to different phases of advancement in the family. Since that time, a few changed details of the life cycle idea have been proposed (Murphy and Staples 1979; Norton 1974; Duvall 1971). The Murphy and Staples variant has been the just a single to create much support in the field because of its capacity to characterize bigger rates of families. While the particular class portrayals of the family life cycle may have been altered to include a more prominent assortment of family ways of life, the commence that family unit needs and needs change contingent upon phases of family advancement remains a sound one.

Utilization of the family life cycle idea to the investigation of vitality utilization conduct has happened on restricted premise. Morrison and Gladhart (1976) recommend that families in youngster raising stages utilize more private vitality than families without kids at either prior or later phases of the life cycle. Shockingly, no quantitative investigation is exhibited to substantiate their discoveries. Bolster for the Morrison and Gladhart conflict, be that as it may, can be found in Fritzsche (1981). Fritzsche looks at family vitality uses by family life cycle organize while controlling for money and number of relatives in work compel utilizing numerous arrangement examination (MCA). A curvilinear example indicating top family vitality consumptions happening amid the kid raising years is archived utilizing both the Wells and Gubar and Murphy and Staples forms of family life cycle. While relative consumption examples are fundamentally the same as crosswise over life cycle organizes in both adaptations, the upside of the Murphy and Staples model is its more noteworthy capacity to characterize respondents with just 3\% unclassifiable contrasted with $10 \%$ for the Wells and Gubar demonstrate.

Fritzsche reasons that family life cycle is an important build for analyzing vitality utilization designs and suggests that vitality protection projects be coordinated at high use portions. Two inadequacies are obvious in this thinking. To 
start with, while family life cycle has all the earmarks of being a profitable prescient measure, no correlation of relative illustrative power is made with other statistic measures.

Of much more prominent significance, be that as it may, is the announcement in regards to strategy suggestions. Fritzsche's attention on aggregate family unit vitality consumptions, including vitality utilized for home warming, high temp water, lights and apparatuses, and gas, accept a unidimensional idea of vitality utilization when a dollar of warmth has an indistinguishable shopper utility from a dollar of fuel. Look into by McDougall, Claxton, and Ritchie (1981) proposes that families make vitality exchange offs between use in the home for warmth or power and use for transportation. High utilization of one vitality source does not infer high utilization of every single other source. From Fritzsche's examination of aggregate vitality utilization it is difficult to decide the relative sums expended in different use settings and direct projects toward particular purchaser needs.

Inside the setting of vitality use to fulfill particular needs. Work be Zimmerman (1981) assessed family unit interest for transportation vitality over the family life cycle. Utilizing the Murphy and Staples display, Zimmerman discovered gas utilization to crest amid center life cycle stages where youngsters were in their late high schoolers. Once out of work compel, family utilization declined definitely. On the off chance that this finding is across the board and families make exchange offs among vitality use settings, one may expect families in later life cycle stages, who invest additional time at home, to utilize more vitality for warmth than family units in prior stages. This proposes promote examination of Fritzsche's approach utilizing just warmth cost could create an altogether different Pattern of results. Past the issue of analyzing the particular vitality use setting is the relationship between relative levels of utilization and preservation. Understanding which family units have found a way to save will help toward projects and items to open market fragments. Investigation of protection practices by Curtin (1976) recommends that family estimate exhibits a curvilinear relationship to preservation. Families with family sizes of three to four individuals revealed more noteworthy past preservation, less expected trouble in future protection, and less demanding modification of current utilization examples to decrease vitality utilize. Moreover, Curtin found that the elderly spoke to the littlest rate revealing warmth preservation and the biggest rate expecting future trouble in moderating or adjusting to vitality deficiencies. If the discoveries of Fritzsche and Curtin are looked at, one may guess that Fritzsche's high consumption families are additionally Curtin's high preservation family units. Ought to this be the situation, unmistakably extraordinary projects could be coordinated to portions which have officially made the primary strides in decreasing their interest for vitality, and show up positively arranged toward proceeding with such endeavors, versus sections which may not be the greatest vitality clients but rather have made no endeavor up 'til now to monitor.

This paper will endeavor to elucidate the relationship between vitality utilization and preservation crosswise over phases of the family life cycle. In tending to the issue of vitality use setting, the concentration of the examination is on home warming uses and warmth related preservation practices. In light of discoveries by Fritzsche and the recommendations of Morrison and Gladhart, the theories concentrate on utilization, relating home warming consumptions and family life style.

\section{RESULTS AND TECHNIQUES}

This review was intended to analyze the relationship between people reacting to a protection battle supported by an extensive electric utility in the New England zone and nonreacting individuals from the all-inclusive community. Selfmanaged mail polls were utilized to assemble the information in February 1981. A known likelihood test was drawn from battle respondents in Massachusetts and New Hampshire. A comparing test of the overall public was drawn from coordinating postal division assignments so that the inside state geographic conveyance of the examples relates nearly. The reaction rate, ascertained given the quantity of usable reactions got partitioned by the aggregate mailing size fewer returns for awful addresses was $75 \%$ for the preservation crusade respondents and $49 \%$ for the all-inclusive community test. Add up to test estimate as the consequence of two finish mailings was $\mathrm{N}=707$. With the end goal of this investigation, where the number of inhabitants in premium is the whole populace of the states, the two examples are weighted to mirror their relative event. This change is made on the premise of aggregate reaction to the protection crusade and its extent to the aggregate number of family units in the zone.

With an end goal to evaluate the similarity of the weighted example and the populace, their relative appropriations on age and pay were analyzed. These two factors were chosen on the premise of their relationship to family life cycle and conceivable effect on yearly home warming expenses. Examination of the specimen circulation on age with those of the New Hampshire and Massachusetts populaces uncovers practically indistinguishable appropriations as per 1980 U.S. Statistics information. Examination of the relative salary circulations utilizing the 1979 Census projections for correlation demonstrates the example to be skewed to some degree higher as one may expect given the way of the information gathering process in spite of the fact that the difference is not serious. Subordinate Variable Respondents were made a request to survey their monetary records and report the aggregate cost of their family unit warm for the past twelve months. Utilization of wood, coal, power, and propane as supplemental wellsprings of warmth was likewise reported and incorporated into aggregate home warming uses.

\section{Free Variables}

Family life cycle, wage, and some contributing livelihoods were the factors chose for examination in view of research by Fritzsche. Extra statistic measures and data identifying with staying size, warm sources, and indoor regulator settings were likewise gathered as a major aspect of the general review. Since the Murphy and Staples conceptualization of family life cycle took into account better arrangement of the specimen and demonstrated an indistinguishable prescient example from the Wells and Gubar treatment of family life cycle in Fritzsche's investigation, the more comprehensive Murphy and Staples configuration is utilized here. Wage is incorporated as a result of its solid positive relationship with warming expenses all through the writing. Some contributing wages may be viewed as a surrogate for the number of individuals at home amid the day and consequently, may be required to shoulder some relationship to warmth uses, nonetheless it has no documentation to bolster it in writing except for Fritzsche's review which does not reference its relative prescient power. Some contributing earnings are like this included here for culmination to permit some examination with its prior utilization. 
In light of the speculation which proposes that preservation steps identified with warmth utilization ought to hold up under a relationship to warming uses, a moment prescient model including a straightforwardly added substance file of ten self-revealed protection measures is incorporated as a free factor notwithstanding family life cycle and pay. It is perceived that the protection practices analyzed in this review have diverse seen relative monetary expenses and individual expenses to shoppers which may recommend the utilization of differential weighting in incorporating the list. The absence of information on customer utilities for-these measures, in any case, recommends that nuttier gritty research is important keeping in mind the end goal to investigate a more complex record of this sort.

\subsection{METHOD}

So as to rethink Fritzsche's examination, a MCA utilizing family life cycle, pay, and some contributing earnings - to anticipate family warming consumptions was run. Notwithstanding assessing relative indicator significance, family life cycle classification implies on warming costs, balanced for money and number of contributing salaries, are given. A prescient moment model joining the protection record is additionally analyzed utilizing MCA.

Table 1:

\begin{tabular}{|l|l|l|l|}
\hline NUMBER & IN. VA. & Signif. Level & $\begin{array}{l}\text { SQ. } \\
\text { PA.COR }\end{array}$ \\
\hline 1 & $\begin{array}{l}\text { Family } \\
\text { life style }\end{array}$ & 0.01 & 0.081 \\
\hline 2 & $\begin{array}{l}\text { Cont. } \\
\text { Income }\end{array}$ & NS & 0.00005 \\
\hline 3 & Incomes & 0.01 & 0.07164 \\
\hline 4 & $\begin{array}{l}\text { Cons. } \\
\text { Index }\end{array}$ & 0.01 & 0.04979 \\
\hline
\end{tabular}

NOTE:

\section{IN.VA= INDEPENDENT VARIABLES}

\section{SQ.PA.COR $=$ SQUARED PART CORRELATION}

\section{CONT. INCOME $=$ CONTRIBUTING INCOME}

\section{CONS. INDEX $=$ CONSERVATION INDEX}

Beyond the relative strength of predictors, a measure of marginal predictive power is also of interest in evaluating the importance of specific explanatory.The squared part correlation shows the variance in the dependent variable (household heat costs) that can be marginally explained by each predictor about the total variance in household heat prices. As shown in Table 1, family life cycle establishes 8 percent of the aggregate fluctuation; wage, 7 percent. Interestingly, the quantity of contributing earnings, with short of what one-portion of one percent minimal illustrative power, clarifies little of the difference in family warm expenses. In rundown, both the beta coefficients and the squared part relationships show that family life cycle is a critical indicator of buyers' warmth consumptions in support of H1. Salary is of to some degree less significance in foreseeing these expenses. Regardless of its consideration in past research by Fritzsche, the quantity of contributing salaries in a family unit adds little to the comprehension of warmth consumption designs. Warming Expenditure Patterns Across Family Life Cycle The normal family consumption for warmth over the whole specimen was $\$ 875.64$ for the year 1980. Deviations from the excellent mean for every family life cycle assemble show up in Table 2. Rather than Fritzsche's decision that family unit vitality costs top amid the full home or center phases of the family life cycle, this investigation of warming consumptions uncovers an alternate example. The deviations crosswise over family life cycle stages-appeared in Table 2 , as produced by the MCA, are balanced for the impacts of salary and number of contributing wages as in the Fritzsche consider. The predominant example demonstrates an immediate positive relationship between time of head of family and warming uses as opposed to the curvilinear example noted by Fritzsche which appeared to be ruled by the impact of family size. The classes which Fritzsche found to have the most astounding aggregate family unit vitality expenses were youthful and middle-age wedded couples with kids. For this situation, these two gatherings have all the earmarks of being great underneath the excellent mean when considering warming expenses (- $\$ 87.13$ and - $\$ 57.83$ separately). More established couples $(+\$ 238.23)$, more seasoned singles $(+\$ 232.29)$, and family units with kids headed by middle-age non-wedded grown-ups $(+780.43)$ report the most noteworthy consumptions over the mean.

\begin{tabular}{|l|c|c|}
\hline Family Life Style & $\begin{array}{l}\text { Heat Cost MCA } \\
\text { Devfactions }\end{array}$ & $\begin{array}{l}\text { Conservation } \\
\text { Deviation }\end{array}$ \\
\hline $\begin{array}{l}\text { Older, married, no } \\
\text { children }\end{array}$ & 238.23 & 0.2 \\
\hline $\begin{array}{l}\text { Middle-aged, } \\
\text { married, children }\end{array}$ & -57.83 & 0.3 \\
\hline $\begin{array}{l}\text { Middle-age, no } \\
\text { married, } \\
\text { children }\end{array}$ & -11.21 & 0.8 \\
\hline $\begin{array}{l}\text { Young, married, } \\
\text { children }\end{array}$ & -87.13 & 0.3 \\
\hline $\begin{array}{l}\text { Young, married, } \\
\text { no children }\end{array}$ & -154.54 & -1.1 \\
\hline $\begin{array}{l}\text { Young, single, no } \\
\text { children }\end{array}$ & -169.54 & -1.1 \\
\hline $\begin{array}{l}\text { Young, WSD, no } \\
\text { children }\end{array}$ & -444.27 & 0.5 \\
\hline $\begin{array}{l}\text { Young, WSD, } \\
\text { children }\end{array}$ & 85.75 & -0.3 \\
\hline $\begin{array}{l}\text { Middle- } \\
\text { age,single-WSD, } \\
\text { no children }\end{array}$ & 6.47 & \\
\hline
\end{tabular}

The peruser ought to be forewarned that this last gathering, which stays the high-end of the conveyance with warming expenses $\$ 780.43$ over the excellent mean, may show precarious appraisals as a result of a little cell estimate. So also, the low-end of the circulation at $\$ 444.27$ underneath the amazing mean for the family unit; without any youngsters headed by youthful, widowed-isolated separated grown-ups likewise displays a little cell measure as does the gathering of youthful, widowed-isolated separated people with kids $(+\$ 85.75)$. It ought to be noticed that while shaky evaluations for these gatherings may come about. The incorporation of these gatherings in the MCA does not impact the soundness of the other class gauges and the announced pattern of expanding 
expenses related to expanding age still holds. It is not necessarily the case that families will essentially utilize more vitality as family life cycle progresses, which would make a period arrangement conclusion from cross-sectional information, yet rather that these more established shoppers seem to have altogether different warming needs from different family units overviewed. The aftereffects of the MCA show that the differential example of warmth expenses crosswise over family life cycle as proposed in $\mathrm{H} 2$ seems, by all accounts, to be available. The anticipated greatness of uses as expressed in $\mathrm{H} 2 \mathrm{a}$ and $\mathrm{H} 2 \mathrm{~b}$ given Fritzsche's work, nonetheless, can't be upheld by this information.

\subsection{Impact of Conservation Efforts on Heat Expenditures}

As opposed to attempting to reach arrangement inferences or make showcasing system proposals to providers of vitality preservation items construct exclusively in light of an investigation of family unit consumptions, it is imperative to consider what activity purchasers may as of now be taking to save or confine warm use. Utilizing the list of self-detailed preservation practices as a measure of shopper activity, the association with warmth cost is analyzed utilizing MCA. The peripheral illustrative force of the protection list, when included as an indicator in the MCA, was .05 bringing about an enhanced balanced $\mathrm{R} 2=.20$. The relative betas for every free factor were observed to be like those in the primary model, as appeared in Table 1. The protection file, which was excluded in the main model, has a beta estimation of .26. All things considered, preservation races third in significance after family life cycle and wage in its capacity to clarify family warming expenses. Each of the three is huge at the .01 level. Assist refinement of list segments and record development ought to prompt to enhanced prescient power and in addition to the more noteworthy comprehension of both utilization and protection.

\section{CONCLUSION}

On the premise of the confirmation displayed, the comprehension of buyer consumptions for home warming is improved by the consideration of the family life cycle build. While just an extremely restricted model is analyzed here, one of the motivations behind this paper is to look at vitality utilization and preservation designs. More prominent accentuation on a forecast of warmth utilization would require a more extensive arrangement of factors including attributes of the private structure. Family life cycle stages, be that as it may, reflect distinctive family needs, needs, and exercises which can clarify warm family consumptions. The information investigated in this review uncover a warmth use design crosswise over family life cycle dissimilar to aggregate vitality utilization beforehand noted in writing. The solid relationship between increments in warmth cost and age proposes diverse bearings for strategy creators and advertisers than does the curvilinear example where add up to vitality costs top with family measure (Fritzsche 1981). Examining vitality utilization inside the particular setting of its use, for example, home warming, elucidates the way of the utilization procedure and helps in the comprehension of customer inspirations and expected advantages from utilization. By growing the investigation of vitality utilization examples to incorporate relating levels of vitality preservation conduct, analysts increase extra understanding into open doors for advancing behavioral change

\section{ACKNOWLEDGMENTS}

Al-Baha University funds this research. It is totally appreciated.

\section{REFERENCES}

[1] Fritzsche, David J. (1981), "An Analysis of Energy Consumption Pattern by Stage of Family Life Cycle,'; Journal of Marketing Research, 18, 227-32.

[2] Murphy, Patrick E., and Staples, William A. (1979), "A Modernized Family Life Cycle," Journal of Consumer Research, 6, 12-22.

[3] Zimmerman, Carol A. (1981), "Household Travel Patterns by Life Cycle Stage," in Consumers and Energy Conservation: International Perspectives on Research and Policy Options, eds. John D. Claxton, C. Dennis Anderson, J.R. Brent Ritchie, and Gordon H.G. McDougall, New York: Praeger, pp. 81-95.

[4] U.S. Department of Energy, Residential Energy Consumption Survey: Conservation, DOE/EIA-0207/3 (1980).

[5] Morrison, Bonnie Maas, and Gladhart, Peter Michael (1976), "Energy and Families: The Crisis and the Response," Journal of Home Economics, 68, 15-18. 